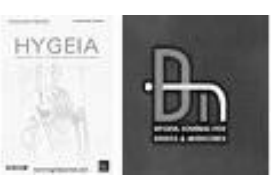

\title{
Formulation and Evaluation of Metaprolol tartarate Non-effervescent Gastric Floating tablets
}

\author{
Bharat W Tekade*, Vinod M Thakare, Umesh T Jadhao, Sandeep B Khatale \\ Department of Pharmaceutics, TVES's Honorable Loksevak MadhukarRao Chaudhari College of Pharmacy, Faizpur, India.
}

\begin{abstract}
Plan: The objective of this study was to develop Gastric floating drug delivery system containing Metoprolol and having a bulk density lower than that of gastric fluid remaining buoyant on the stomach contents.

Preface: Metaprolol tartarate is having short to moderate half life 3-7 hrs, low bioavailability hence it is worth able to formulate Metaprolol in floating drug delivery. The GRDDS can improve the controlled delivery of the drugs which exhibit an absorption window by continuously releasing the drug for a prolonged period before it reaches its absorption site, thus ensuring its optimal bioavailability

Methodology: Percentage drug content in all floating tablet formulations was found to be $95.85 \%$ to $103.33 \%$ which was within Pharmacopoeial limit. In- vitro drug release profile from all formulations (F1-F10) showed sustained release of Metoprolol Tartarate over a period of 10 hours.

Outcome: Among all the formulation, F3 showed drug release up to $94.71 \%$ at the end of 10 hours. The mechanism of the drug release from F3 was anomalous transport, first order release kinetics. Stability studies on optimized batch showed no significant effect on physical properties, drug content, floating behavior and drug release.
\end{abstract}

Keywords:

Gastro retentive floating tablets, Buoyancy, Metoprolol Tartarate, HPMC, Kinetic studies.

\section{INTRODUCTION}

There has been considerable research over the last decade on the possibility of controlled and site specific delivery to the GIT by controlling the gastrointestinal transit of orally administered dosage forms using gastro retentive drug delivery system (GRDDS) ${ }^{1}$. Such GRDDS possess the ability of retaining the dosage forms in gastrointestinal tract (GIT) particularly, in the stomach for long period ${ }^{2}$ the transit time in GIT i.e., from the mouth to the anus, varies from one person to another. It also depends upon the physical properties of the object ingested and the physiological conditions of the alimentary canal. 
Several drugs are absorbed to the most extent in the upper part of the small intestine ${ }^{2}$. Many drugs show poor bioavailability (BA) in the presence of intestinal metabolic enzymes like cytochrome P450 (CYP3A), abundantly present in the intestinal epithelium. Their activity decreases longitudinally along the small intestine, with levels rising slightly from the duodenum to the jejunum and declining in the ileum and $\operatorname{colon}^{3}$. Drugs having site-specific absorption are difficult to design as oral CRDDS because only the drug released in the region preceding and in close vicinity to the absorption window is available for absorption. After crossing the absorption window, the released drug goes waste with negligible or no absorption. This phenomenon considerably decreases the time available for drug absorption after its release and expose the success of the delivery system. ${ }^{4}$ The GRDDS can improve the controlled delivery of the drugs which exhibit an absorption window by continuously releasing the drug for a prolonged period before it reaches its absorption site, thus ensuring its optimal bioavailability. Metaprolol tartarate is having short to moderate half life i.e. 3-7 hrs, low bioavailability hence it is worth able to formulate Metaprolol ${ }^{5,6}$. in floating drug delivery. The objective of this study was to developed Gastric floating drug delivery system containing metoprolol and having a bulk density lower than that of gastric fluid and remaining buoyant on the stomach contents. To achieve the objective low density polymers such as HPMC 5 cps, HPMC K15M and aerosil are used.

\section{MATERIALS AND METHODS}

\subsection{Materials}

Metaprolol Tartarate was obtained as kind gift sample from Glenmark Ltd,Aurangabad, Hydroxy Propyl Methyl Cellulose and Aerosil were obtained from Wockhard Limited, Aurangabad All other chemicals/reagents used were of analytical grade, available commercially and used as such without further processing.

\subsubsection{Preparation of Floating tablets of Metoprolol Tartarate:}

Floating hydrophilic matrix tablets were prepared by direct compression technique using different polymers with varying concentration of selected different excipients. The tablets were compressed using flat punch on a rotary punching machine Jaguar Ltd, Mumbai (JMD4-8). During preliminary studies, various formulations were prepared using different concentration of polymers and floating agent. This was done to aid in choosing the limits for the ingredients for further evaluation. Pre-optimization investigation containing different concentration of polymers and floating agent.

2.1.2. Pre-Compression Characteristics ${ }^{7,8}$. The following parameters are determined.

2.1.2.1. Bulk density: The ratio of mass (weight) to volume is known as the bulk density of material ${ }^{7}$. The bulk density of a powder depends on particle size distribution, particle. The equation for determining the bulk density is

$$
\rho \mathrm{b}=\frac{\mathrm{M}}{\mathrm{V}} \text { Where, } M \text { - Mass of particles and } V \text { - Total volume of packing. }
$$




\subsubsection{Tapped density}

Tapped density is determined by placing a graduated cylinder containing a known mass of drug on a mechanical tapper apparatus, which is operated for fixed number of taps $(\sim 1000)$ until a powder bed volume has reached the minimum. Using the weight of drug in cylinder and tapped volume the tapped density is determined ${ }^{9}$.

$$
\mathrm{TD}=\text { weight } \text { of powder/ Tapped volume }
$$

Both loose bulk density (LBD) and tapped bulk density (TBD) were determined by using same equation.

\subsubsection{Angle of repose}

Angle of repose is defined as the maximum angle possible between the surface of pile of powder and horizontal plane. The angle of repose was determined by the funnel method. A funnel with $10 \mathrm{~mm}$ inner diameter of stem was fixed at a height of $2.5 \mathrm{~cm}$ over the platform. About $10 \mathrm{gm}$ of sample was slowly passed along the wall of the funnel till the tip of the pile formed and touches the stem of the funnel. The powder was allowed to flow through the funnel freely onto the surface. The diameter of the powder cone was measured. A rough circle was drawn around the pile base and the radius of the powder cone was measured ${ }^{9}$. Calculated by following formula:

$\operatorname{Tan} \theta=\mathrm{H} / \mathrm{R}$ Where, $\theta=$ angle of repose, $h=$ height of the pile, $r=$ average radius of the powder conc.

\subsubsection{Compressibility index}

The compressibility index of the granules was determined by Carr's compressibility index ${ }^{10}$.

$$
\text { Carr's Index }=[(T B D-L B D) \times 100 / T B D]
$$

\subsection{Evaluation of Metoprolol tartarate floating tablet:}

\subsubsection{Hardness}

It is defined as the force applied across the diameter of the tablet in order to break the tablet. To perform this test, a tablet is placed between two anvils of hardness tester; force is applied to the anvils and the crushing strength that just cause the tablet to break is recorded. Hardness is sometimes termed as tablet crushing strength. This parameter is important to know that the tablet has sufficient strength to withstand mechanical shocks of handling in manufacture, packaging and shipping ${ }^{7,8}$.

\subsubsection{Thickness and Diameter:}

It is determined for five tablets from a batch by using a calibrated Vernier Caliper and the result is given in $\mathrm{mm}$. 


\subsubsection{Friability}

It is intended to determine the loss of mass under defined conditions. The friability of uncoated tablets is determined by using Electrolab friabilator in the laboratory. This device subjects a number of tablets to the combined effects of abrasion and shock by utilizing a plastic chamber that revolves at $25 \mathrm{rpm}$, dropping the tablets a distance of six inches with each operation for 100 revolutions ${ }^{7}$. The tablets are then dusted and reweighed. Tablets that loose less than $0.5-1 \%$ of the weight of the tablets tested are considered to be acceptable for most products. It is expressed as the loss of mass and it is calculated as a percentage of initial mass. The extent of friability was calculated using following formula,

$$
\% \text { Friability }=\frac{\text { Initial Weight of Tablets }- \text { Final Weight of Tablets }}{\text { Final Weight of Tablets }}
$$

(The values for both Hardness \& Friability can together indicate the mechanical strength of tablet.)

\subsubsection{Weight Variation Test}

Weight variation of tablets is calculated by weighing 20 tablets individually and determining the average weight. Tablet meets the test if not more than two of the individual weights deviate from percentage limits ${ }^{7}$.

\subsubsection{Drug content uniformity}

The tablets were weighed and taken in a mortar and crushed to powder. A quantity of powder weighed equivalent to $100 \mathrm{mg}$ of Metoprolol tartarate was taken in a $100 \mathrm{ml}$ volumetric flask and $0.1 \mathrm{~N}$ HCL was added. It was then heated at $60^{\circ} \mathrm{C}$ for 30 minutes. The solution was filtered using membrane filter $(0.45 \mathrm{~nm})$ and then its absorbance was measured at $274 \mathrm{~nm}^{11}$. The amount of drug was calculated using standard graph.

\subsubsection{Swelling Studies}

Tablet were weighed individually (recorded as W1) and placed separately in Petri dish containing $5 \mathrm{~mL}$ of phosphate buffer ( $\mathrm{pH}$ 1.2) solution. At regular intervals (1, 2, 3, 4 and 5 hours), the tablets was removed from the Petri dish and excess surface water was removed carefully using the filter paper ${ }^{12-14}$. The swollen tablets were then reweighed (W2), and swelling index (SI) was calculated using formula as

$$
\text { Swelling Index }=\quad S I=\frac{W_{2}-\mathrm{W}_{1}}{\mathrm{~W}_{1}}
$$

\subsubsection{In vitro floating study}

The in vitro floating behavior of the tablets was studied by placing them in $900 \mathrm{ml}$ of plastic containers filled with $900 \mathrm{ml}$ of $0.1 \mathrm{~N} \mathrm{HCl} .\left(\mathrm{pH} 1.2,37 \pm 0.5^{\circ} \mathrm{C}\right.$ ). The floating lag times (time period between placing the tablet in the medium and tablet floating) and floating durations of the tablets were determined by visual observation ${ }^{15}$. 


\subsubsection{In vitro dissolution studies}

In-vitro drug release studies of Metoprolol tartarate were studies using dissolution apparatus USP type II paddle method with a stirring speed of $75 \mathrm{rpm}$ at $37 \pm 0.5^{\circ} \mathrm{C}$ in $900 \mathrm{ml}$ of (pH 1.2) simulated gastric fluid for 10 hours. The samples were taken at pre selected time intervals with replacement of equal volume of dissolution media. The collected samples were diluted and the absorbance was measured spectrophotometrically at $274 \mathrm{~nm}$. The percentage of Metoprolol tartarate released at various time intervals were calculated from the standard graph ${ }^{10,11}$.

\subsubsection{Accelerated Stability Studies}

Stability of medicinal products may be defined as the capability of a particular formulation in a specific container to remain within its physical, chemical, microbial, therapeutic and toxicological specification, i.e. stability of drug is its ability to resists deterioration. $90 \%$ of labeled potency is generally recognized as the minimum acceptable potency level. Deterioration of drug may take several forms arising from changes in physical, chemical and microbiological properties. The changes may affect the therapeutic value of preparation or increase its toxicity. The formulated Metoprolol tartarate floating tablets were studied for its stability as per ICH guidelines where, the tablets are to be tested for its efficiency of release for long term period ${ }^{16,17}$. As per ICH guidelines samples were stored at different storage conditions.

\subsubsection{Differential scanning calorimetry}

Thermal behavior of drug and polymers were studied by differential scanning calorimetry (DSC) using DSC 7 (Perkin-Elmer, Norwalk, CT). The instruments were calibrated using indium standards. Accurately weighed samples $(5-10 \mathrm{mg})$ were hermetically sealed in flat bottom Aluminum Standard $40 \mu \mathrm{l}$ pans and heated from 50 to $300^{\circ} \mathrm{C}$ at a rate of $10^{\circ} \mathrm{C} / \mathrm{min}$. under an atmosphere of nitrogen. Melting endotherms of drug, placebo and optimized formulation were determined in the same way. Thermo grams were normalized and rescaled as needed before overlapping. An empty Aluminum pan was used as reference ${ }^{18,19}$.

\subsubsection{FT-IR spectrophotometer}

It was carried out to check for the possible Drug-Excipients interaction. The IR absorption band in $\mathrm{cm}^{-1}$ of the drug and excipients used in the study were similar ${ }^{20,21}$. The IR spectrum did not show presence of any additional peaks for new functional groups indicating no chemical interaction between Metaprolol tartarate \& the used polymers. From the IR spectrum of the Drug and polymer it was found that there is no or negligible change is observed in the spectrum (which shown in above figures) so, there was no chemical interaction observed between drug Metaprolol tartarate and excipients (polymers). In this way compatibility was studied between drug and excipient and they are stable. 
Bharat W Tekade et al.

Table 1: Formulation of floating tablet

\begin{tabular}{|c|c|c|c|c|c|c|c|c|c|c|}
\hline \multirow{2}{*}{$\begin{array}{c}\text { Ingredient } \\
(\mathrm{Mg})\end{array}$} & \multicolumn{10}{|c|}{ Batches } \\
\hline & $F 1$ & $F 2$ & $F 3$ & $F 4$ & $F 5$ & F6 & $F 7$ & $F 8$ & $F 9$ & F10 \\
\hline Drug & 100 & 100 & 100 & 100 & 100 & 100 & 100 & 100 & 100 & 100 \\
\hline $\begin{array}{c}\text { HPMC } \\
5 \mathrm{cps}\end{array}$ & 200 & 200 & 200 & 210 & 220 & -- & -- & -- & -- & -- \\
\hline $\begin{array}{l}\text { HPMC } \\
\text { K15M }\end{array}$ & -- & -- & -- & -- & -- & 150 & 160 & 170 & 180 & 190 \\
\hline Aerosil & 4 & 4.5 & 5 & 5 & 5 & 5 & 5 & 5 & 5 & 5 \\
\hline $\mathrm{MCC}$ & 15 & 15 & 15 & 15.5 & 16 & 15 & 15 & 15 & 15 & 15 \\
\hline
\end{tabular}

Table 2: Evaluation of precompression parameters of formulations.

\begin{tabular}{cccccc}
\hline Batches & $\begin{array}{c}\text { Angle of Repose } \\
\pm \text { SD }\end{array}$ & Bulk Density & $\begin{array}{c}\text { Tapped } \\
\text { Density }\end{array}$ & $\begin{array}{c}\text { Compressibility } \\
\text { Index }\end{array}$ & Hausner Ratio \\
\hline F1 & $26.97 \pm 0.89$ & $0.75 \pm 0.015$ & $0.86 \pm 0.015$ & $15.31 \pm 0.53$ & $1.150 \pm 0.007$ \\
F2 & $27.91 \pm 0.92$ & $0.77 \pm 0.01$ & $0.87 \pm 0.026$ & $17.06 \pm 0.46$ & $1.135 \pm 0.009$ \\
F3 & $25.76 \pm 0.90$ & $0.78 \pm 0.01$ & $0.86 \pm 0.023$ & $14.03 \pm 1.66$ & $1.105 \pm 0.032$ \\
F4 & $28.11 \pm 0.91$ & $0.78 \pm 0.015$ & $0.87 \pm 0.016$ & $19.23 \pm 1.73$ & $1.125 \pm 0.028$ \\
F5 & $25.8 \pm 0.86$ & $0.76 \pm 0.01$ & $0.87 \pm 0.01$ & $18.72 \pm 0.46$ & $1.229 \pm 0.006$ \\
F6 & $28.3 \pm 1.52$ & $0.63 \pm 0.014$ & $0.78 \pm 0.015$ & $20.25 \pm 0.79$ & $1.238 \pm 0.023$ \\
F7 & $24.54 \pm 0.61$ & $0.62 \pm 0.005$ & $0.76 \pm 0.01$ & $18.42 \pm 0.55$ & $1.227 \pm 0.028$ \\
F8 & $28.72 \pm 0.36$ & $0.63 \pm 0.36$ & $0.79 \pm 0.89$ & $19.57 \pm 0.42$ & $1.22 \pm 0.013$ \\
F9 & $25.76 \pm 0.90$ & $0.65 \pm 0.86$ & $0.79 \pm 0.87$ & $16.72 \pm 0.90$ & $1.215 \pm 0.013$ \\
F10 & $28.39 \pm 0.91$ & $0.64 \pm 0.005$ & $0.78 \pm 0.01$ & $18.44 \pm 0.55$ & $1.217 \pm 0.028$ \\
\hline$*(n=3)$ & & & &
\end{tabular}

Table 3: Evaluation of Post Compression Parameters.

\begin{tabular}{cccccc}
\hline Batches & Thickness & $\begin{array}{c}\text { Hardness } \\
\left(\mathrm{kg} / \mathrm{cm}^{2}\right)\end{array}$ & $\begin{array}{c}\text { Friability } \\
(\%)\end{array}$ & $\begin{array}{c}\text { Weight Uniformity } \\
(\mathrm{mg})\end{array}$ & $\begin{array}{c}\text { Floating } \\
\text { Time }(\mathrm{hrs})\end{array}$ \\
\hline F1 & $3.396 \pm 0.035$ & $5.4 \pm 0.458$ & $0.95 \pm 0.03$ & $320.56 \pm 1.63$ & 11.0 \\
F2 & $3.405 \pm 0.030$ & $5.26 \pm 0.73$ & $0.92 \pm 0.03$ & $321.31 \pm 1.968$ & 11.0 \\
F3 & $3.396 \pm 0.032$ & $5.75 \pm 0.45$ & $0.49 \pm 0.02$ & $320.72 \pm 1.202$ & 12.0 \\
F4 & $3.408 \pm 0.033$ & $5.34 \pm 0.51$ & $0.98 \pm 0.03$ & $334.34 \pm 1.196$ & 12.0 \\
F5 & $3.402 \pm 0.032$ & $5.65 \pm 0.62$ & $0.90 \pm 0.02$ & $339.57 \pm 1.005$ & 12.0 \\
F6 & $3.596 \pm 0.135$ & $5.4 \pm 0.423$ & $0.89 \pm 0.02$ & $272.46 \pm 1.38$ & 11.0 \\
F7 & $3.325 \pm 0.050$ & $5.3 \pm 0.56$ & $0.86 \pm 0.05$ & $279.21 \pm 1.81$ & 11.0 \\
F8 & $3.356 \pm 0.062$ & $5.8 \pm 0.098$ & $0.95 \pm 0.05$ & $290.76 \pm 1.291$ & 11.0 \\
F9 & $3.386 \pm 0.065$ & $6.23 \pm 0.51$ & $0.87 \pm 0.02$ & $301.80 \pm 1.643$ & 11.0 \\
F10 & $3.435 \pm 0.130$ & $5.44 \pm 0.12$ & $0.85 \pm 0.09$ & $311.09 \pm 1.819$ & 12.0 \\
\hline
\end{tabular}




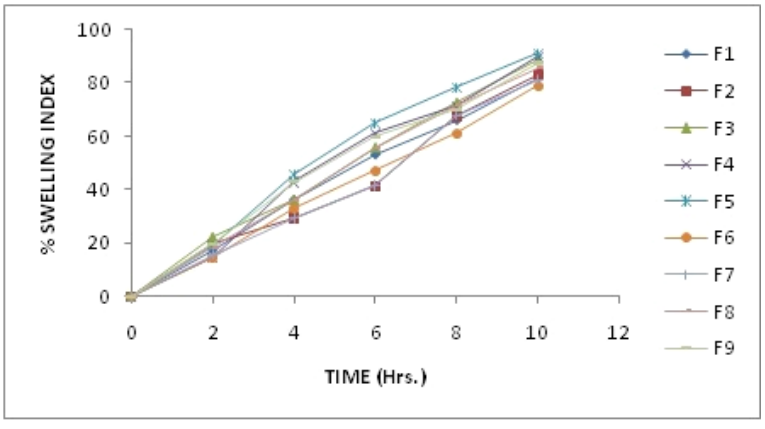

Fig. 1:\% Swelling index vs Time in hours.

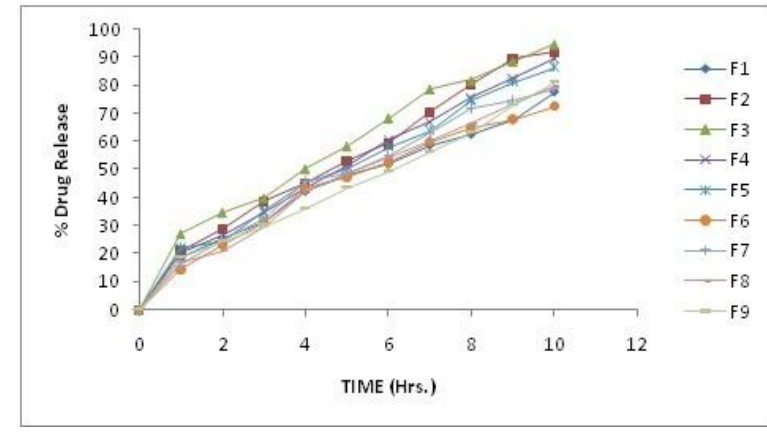

Fig. 2:\% Drug release Vs Time of F1-F9.

Table 4: Kinetic data for the prepared batches

\begin{tabular}{ccccc}
\hline Formulations & Best Fit Model & $r^{2}$ & $K$ & $n$ (Peppas) \\
\hline F1 & Matrix & 0.9847 & 21.9537 & 0.9957 \\
F2 & Peppas & 0.9868 & 20.2246 & 0.9727 \\
F3 & Matrix & 0.9941 & 28.1572 & 0.9946 \\
F4 & Matrix & 0.9761 & 24.7739 & 0.9821 \\
F5 & Matrix & 0.9765 & 25.09 & 0.9799 \\
F6 & Peppas & 0.9823 & 21.8962 & 0.9881 \\
F7 & Peppas & 0.9776 & 23.4249 & 0.9918 \\
F8 & Matrix & 0.9711 & 22.576 & 0.9889 \\
F9 & Matrix & 0.9629 & 21.843 & 0.9838 \\
F10 & Matrix & 0.9879 & 22.071 & 0.9824 \\
\hline
\end{tabular}

Table 5: stability studies of F3.

\begin{tabular}{ccccc}
\hline Parameters & & \multicolumn{3}{c}{ Days } \\
& Initial & 15 & 30 & 45 \\
\hline Colour & White & No Change & No Change & No Change \\
Hardness & $5.62 \pm 0.28$ & $5.56 \pm 0.73$ & $5.37 \pm 0.41$ & $5.49 \pm 0.76$ \\
Drug Content $(\%)$ & $100.1 \pm 0.37$ & $99.97 \pm 0.15$ & $99.48 \pm 1.02$ & $99.19 \pm 0.72$ \\
\% Drug Release & $94.10 \pm 0.48$ & $93.83 \pm 0.14$ & $93.42 \pm 1.03$ & $93.22 \pm 0.85$ \\
\hline
\end{tabular}




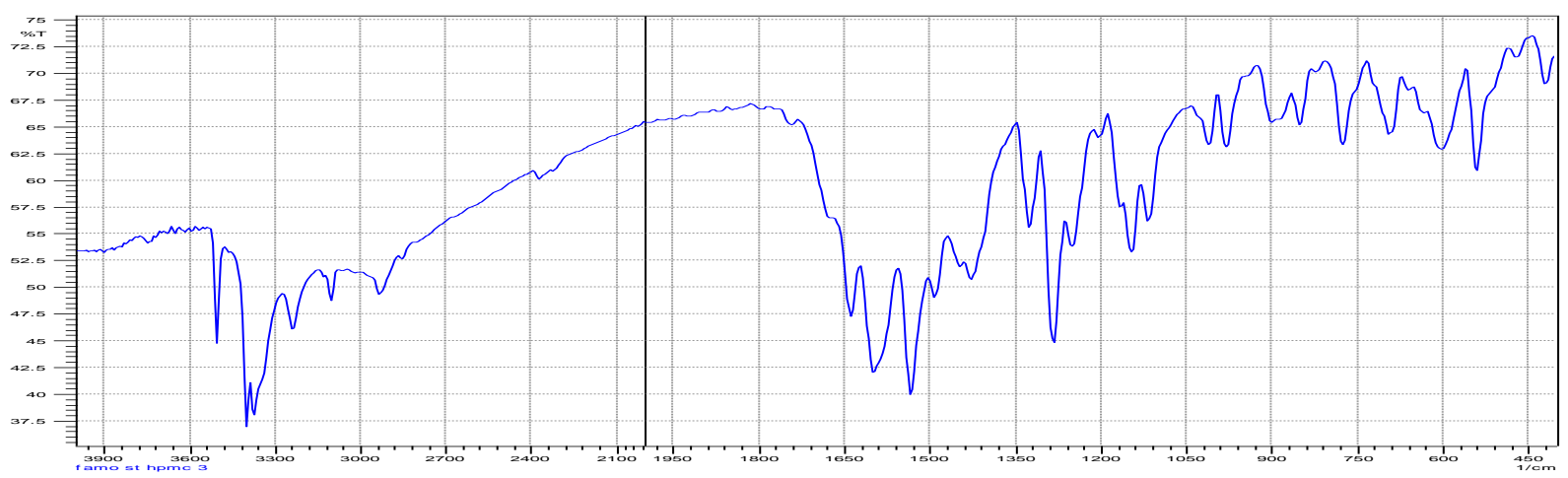

Fig. 3: IR spectrum of Metaprolol Tartarate

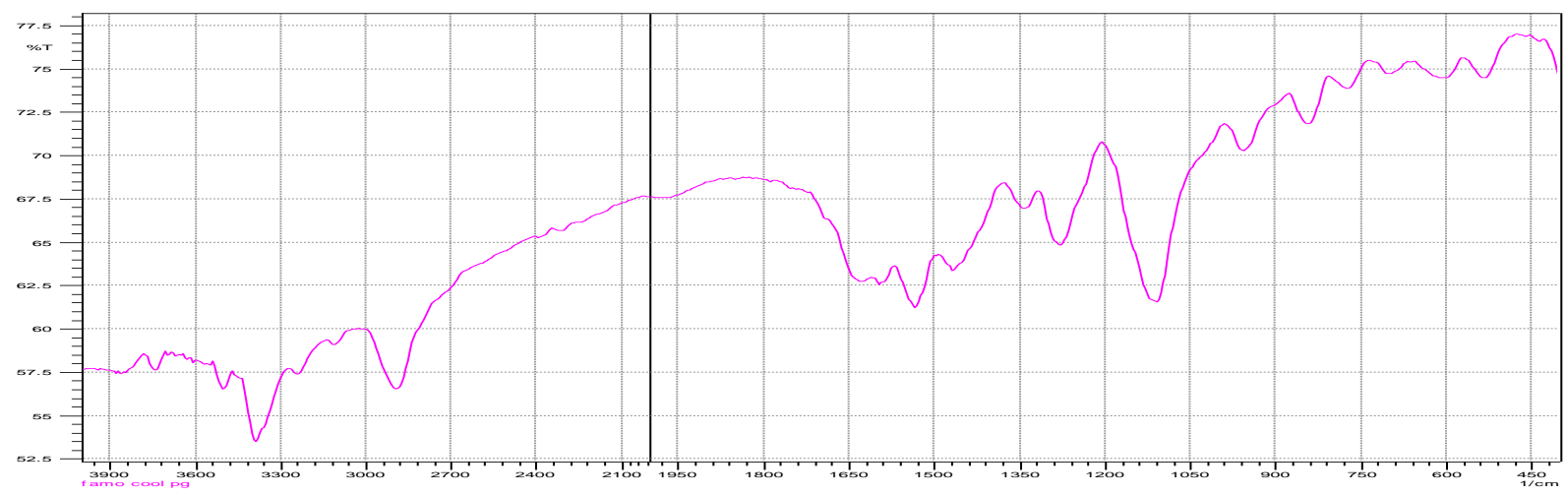

Fig 4: IR spectrum of Metaprolol Tartarate and HPMC

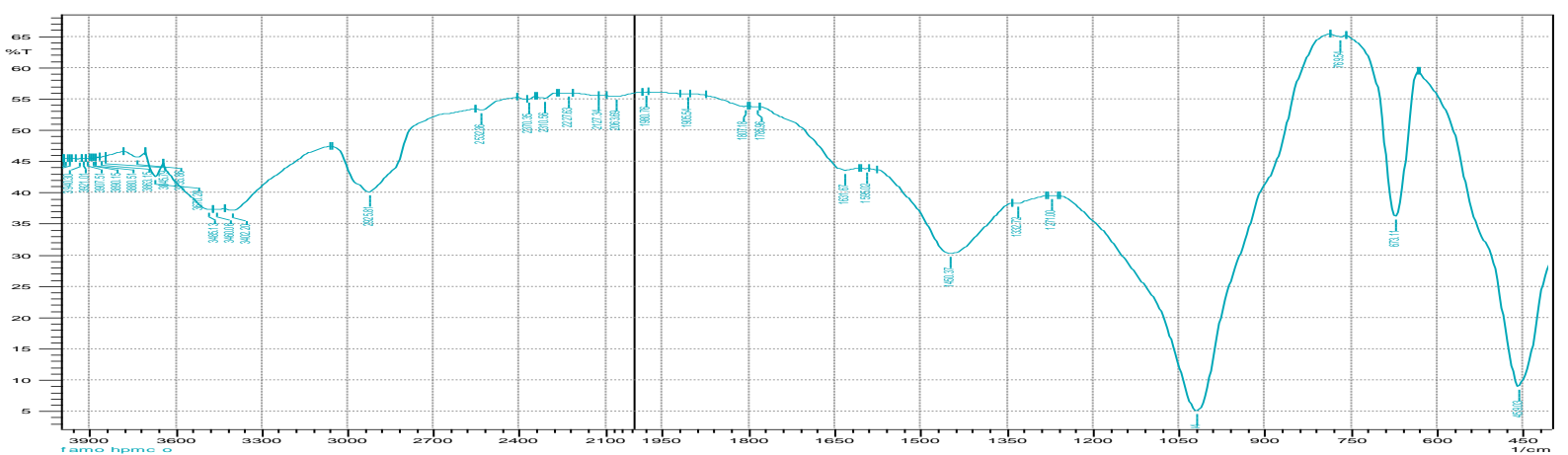

Fig.5: IR spectrum of HPMC. 
Differential Scanning Calorimetry (DSC Analysis)

DSC thermogram of the optimized formulation showed that there is was no any major difference in onset temperature and peak temperature, when compared with pure drug thermogram. The DSC thermogram of pure drug, polymer and optimized batch are shown in following figure;

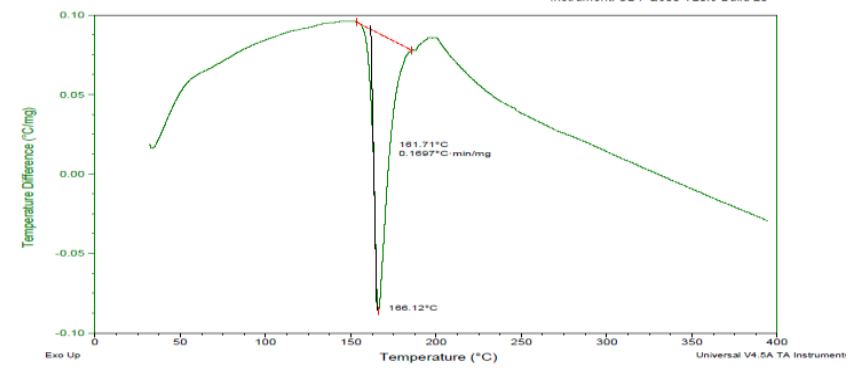

Fig.6

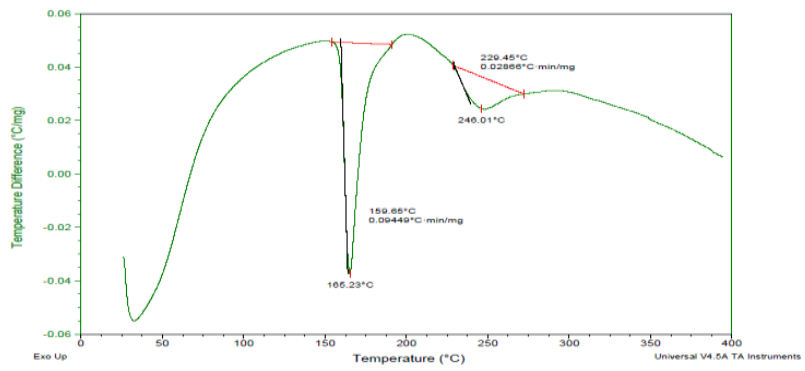

Fig.7

Fig. 6. DSC thermograms of drug Metaprolol tartarate.

Fig. 7. DSC thermograms of drug Metaprolol tartarate + HPMC 5cps.

\section{RESULT AND DISCUSSION}

Powder blend was evaluated for the angle of repose value which was found to be in the range of $24.23-28.7$ indicating powder flow for all the eight formulations were good. Bulk density for all eight formulations was found to be in the range of $0.61-0.80$ while tapped density was in the range of $0.76-0.88$. The percent compressibility index for all eight formulations was found to be 14.03. -19.23. These results indicated that the powder had well to fairly acceptable flow property.

The thickness of tablet indicates that, die fill was uniform. The thickness depends on the size of the punches $(10 \mathrm{~mm})$ and the weight of one tablet $(350 \mathrm{mg})$. The thickness of formula from FT1 to FT8 was found to be 3 $\pm 0.1 \mathrm{~mm}$ and hardness was found to be $5 \pm 1 \mathrm{Kg} / \mathrm{cm}^{2}$. The thickness of tablet of optimized formulation (FT2.) was found to be $3 \pm 0.5 \mathrm{~mm}$ and the hardness was found to be $4.8-5.7 \mathrm{Kg} / \mathrm{cm}^{2}$. It has good mechanical strength. Percentage weight loss of the 10 tablets of each formulation was measured and found to be in the range of $0.62-0.93 \%$ which was under acceptable limit i.e. in between $0.5-1 \%$.

Swelling index was calculated with respect to time. Swelling index increased as the weight gain by the tablets increased proportionally with the rate of hydration. The formulation batch containing higher HPMC and aerosol showed higher swelling index. From the results obtained, it was observed that the increased concentration of polymers increases the swelling indices. 
In- vitro drug release profile from all formulations showed sustained release of Metaprolol Tartarate over a period of 10 hours. Among all the formulation, F3 showed drug release up to $94.71 \%$ at the end of 10 hours. The cumulative percentage drug release was decreased by increase in polymer concentrations of HPMC.The mechanism of the drug release from F14 was anomalous transport, first order release kinetics which met the requirements of sustained drug delivery system.

Stability studies at temperature $40^{\circ} \mathrm{C} / 75 \% \mathrm{RH}$ for 15 , 30and 45 days on optimized batch showed no significant effect on physical properties, drug content, floating behaviour and drug release.

\section{CONCLUSION}

The present study was carried out to develop the floating drug delivery with sustained release of Metoprolol Tartarate using HPMC 5cps, Aerosil and MCC polymers. In-vitro dissolution studies showed good percent yield, good buoyancy and release up to $10 \mathrm{hrs,} \mathrm{followed} \mathrm{by} \mathrm{the} \mathrm{non-} \mathrm{Fickian} \mathrm{transport.} \mathrm{Thus,} \mathrm{results} \mathrm{of} \mathrm{the}$ current study clearly indicate, a promising potential of the Metoprolol Tartarate floating system as an alternative to the conventional dosage form. However, further clinical studies are needed to assess the utility of this system. At the end, from the experiments carried out and results obtained, it can be concluded that the developed formulations achieved the objective of the investigation.

\section{REFERENCES}

1. Rouge N, Buri, P, Doelker E. Drug absorption sites in the gastrointestinal tract and dosages forms for site-specific delivery. Int J Pharm. 1996. 117-139.

2. William AS, Vijayaragavan.C, Purohit D. Formulation and Evaluation of floating matrix tablets of clarithromycin using different grades of HPMC. Int J Pharm Sci, 2013; Vol 5(3): 174-176.

3. Arora S, Javed A, Khar R, Ahuja A. Floating drug delivery systems: A Review, AAPS Pharm SciTech 2005, $372-390$.

4. Bhatt DA, Pethe AM, Mucoadhesive Drug Delivery Systems : An Overview Journal of Pharmacy Research 2010 Vol.3(8): 1743-1747

5. Jadhao UT, Thakare VM, Tekade BW: Development and in-vitro evaluation of intra gastric cefadroxil monohydrate floating tablet. Der Pharmacia Sinica, 2013; 4(4):141-150.

6. Bansal A, Chawla G, Gupta, P, Koradia V, Gastro retention a means to address regional variability in intestinal drug absorption. Pharmaceutical technology, 2003; 7: 50-68.

7. Mayavanshi AV, Gajjar SS. Floating drug delivery systems to increase gastric retention of drugs: A Review. Res $J$ Pharm Tech 2008; 1:345-48.

8. Shah SH, Patel JK, Patel NV. Stomach specific floating drug delivery system: A Review. Int J PharmTech Res 2009; 1:62333.

9. Lachman L, Liberman H. A., Kanig J. L.Tablet.The Theory and Practice of Industrial Pharmacy. $3^{\text {rd }}$ edition. Mumbai, Varghese publishing house, 1990; 293-302.

10. Aulton ME. The Design and Manufacture of Medicines. Aulton's Pharmaceuticals, $3^{\text {rd }}$ Edition. Churchill Livingstone Elsevier, 2007 175-177, 465-466. 
11. Banker SG, Anderson RN. Tablets. In, Lachman L, Liberman AH, Kanig LJ. Text book of the theory and practice of industrial pharmacy, $3^{\text {rd }}$ edition. Mumbai, Varghese Publication House, 1991; 317-324.

12. Alfred Martin, Games Swarbrik Physical pharmacy, physical chemical principal of pharmaceutical sci. $3^{\text {rd }}$ ed. Varghese publication house 1991 518-519.

13. United States of pharmacopoeia. Washington, board of trustee publisher, 2004; 1811-1820.

14. Nakhat PD,Kondawar AA, Rathi LG,Yeole PG. Development and In-Vitro Evaluation of Buccoadhesive Tablet of Metoprolol Tartrate.; Indian J. Pharm. Sci. 2010 ;70(1):121-124.

15. Stops F, Fell JT, Collett JH. The use of citric acid to prolong the in vivo gastro-retention of a floating dosage form in the fasted state. Int J Pharm. 2006; 308:8-13

16. Timmermans J, Moes A J. Factors controlling and gastric retention capabilities of floating matrix capsules. J Pharm Sci. 1994; 83: 18-24.

17. Rosa M, Zia H, Rhodes T, Dosing and testing in vitro of a bioadhesive and floating drug delivery system for oral application, Int.J Pharm.,1994 105:65-70.

18. ICH Harmonised Tripartite Guideline. Stability testing of new drug substances and products Q1A (R2). Current Step 4, 2003 3-9.

19. Watson DG. Pharmaceutical Analysis - A textbook for pharmacy students and pharmaceutical chemists, $1^{\text {st }}$ edition. London, Churchill Livingstone, 1999; 100-103.

20. Florey K. analytical profile of drug substances, New Jersey, academic press Elsevier; 2005; 4: 468-493.

21. Stuart B, spectral analysis. Infrared spectroscopy fundamental and application, John willey and son, 2004; 46-63.

22. Chatwal GR, Anand SK. instrumental method of chemical analysis. New Delhi, Himalaya publishing house, 2004; $2.29-2.51$. 